\title{
HARMONISASI KAPABILITAS MANAJEMEN, AKSES PENDANAAN, DAN NILAI PERSONAL ENTREPRENEUR DALAM MENINGKATKAN INOVASI DAN KINERJA UKM
}

\author{
Rima Parawati Bala \\ Staf Pengajar \\ Program Studi Manajemen, STIE Atma Bhakti, Surakarta \\ e-mail : rimaparawatibala@gmail.com \\ Sri Lastuti \\ Staf Pengajar \\ Program Studi Manajemen, STIE Atma Bhakti, Surakarta \\ e-mail : sri.lastuti@gmail.com
}

\begin{abstract}
Maintaining or even improving the performance of SMEs is faced with limited management capabilities that can cause SMEs to face difficulties in responding to existing opportunities, while problems in the financial sector cause difficulties in accessing capital for SMEs which will have an impact on SMEs in carrying out operational activities. In addition, the personal value of an entrepreneur is very important for the innovation and performance of SMEs because it affects the way individuals think, feel and act in carrying out their business activities. The combination of entrepreneurial personal values and organizational resources will build a positive basis for attitudes towards the innovative nature of the organization. Meanwhile, innovation is required to be sustainable to be able to improve the performance of SMEs. This study aims to test empirically several factors that can improve innovation and performance of SMEs. The research sample was 125 UKM in Surakarta City. Non random sampling is used as a sampling method with a sample selection technique, namely convenience sampling. Data analysis using Structural Equation Modeling (SEM) with the help of smartpls. The results showed that management capabilities, access to funding and personal values of the interpreneur had a positive influence on innovation and performance of SMEs. Innovation as one of the crucial things in SMEs also has a positive influence on the performance of SMEs.
\end{abstract}

\begin{abstract}
ABSTRAK
Mempertahankan atau bahkan meningkatkan kinerja UKM dihadapkan pada keterbatasan kapabilitas manajemen yang dapat menyebabkan UKM menghadapi kesulitan dalam merespon peluang yang ada sedangkan masalah di bidang keuangan menyebabkan kesulitan mengakses permodalan bagi UKM yang akan berdampak tersendatnya UKM dalam menjalankan kegiatan operasional. Selain itu nilai personal entrepreneur sangat penting bagi inovasi dan kinerja UKM karena mempengaruhi cara individu berpikir, merasa, dan bertindak dalam menjalankan kegiatan bisnisnya. Kombinasi nilai personal entreprenur dan sumber daya organisasi akan membangun dasar positif untuk bersikap terhadap sifat inovasi organisasi. Sementara itu inovasi dituntut berkelanjutan untuk mampu meningkatkan kinerja UKM. Penelitian ini bertujuan untuk menguji secara empiris beberapa faktor yang mampu meningkatkan inovasi dan kinerja UKM. Sampel penelitian sebanyak 125 UKM di Kota Surakarta. Non random sampling digunakan sebagai metode pengambilan sampling dengan teknik pemilihan sampel yaitu convinience sampling. Analisis data menggunakan Structural
\end{abstract}




\section{Buletin Ekonomi}

Equation Modeling (SEM) dengan bantuan smartpls. Hasil penelitian menunjukkan bahwa kapabilitas manajemen, akses pendanaan dan nilai personal interpreneur memberi pengaruh positif pada inovasi dan kinerja UKM. Inovasi sebagai salah satu hal krusial dalam UKM juga memberi pengaruh positif pada kinerja UKM.

Kata Kunci : Kapabilitas manajemen, akses pendanaan, nilai personal entrepreneur, inovasi, kinerja UKMi

\section{PENDAHULUAN}

Usaha Kecil dan Menengah (UKM) secara global diakui sebagai urat nadi yang penting dan melekat dalam transformasi sosio-ekonomi suatu negara (Sambo, 2015). UKM mampu memasuki semua sektor dalam industri yang ada sehingga UKM mampu menyediakan $80 \%$ lapangan kerja yang dibutuhkan oleh masyarakat di Indonesia. Selain itu UKM diharapkan mampu mengikis kemiskinan dan meningkatkan pembangunan berkelanjutan di semua bidang kehidupan (Mugwon, 2007). UKM berperan dalam menompang perekonomian Indonesia melalui inovasi, dan produktivitas sumber daya (Chittithaworn, 2011; Turyahebwa, 2013). Namun dengan segala keistimewaan keberadaan UKM , UKM masih dihadapkan pada berbagai kendala yang menghambat eksistensinya. Oleh karena itu, pemerintah berupaya mengembangkan berbagai program yang mendukung usaha dan kinerja UKM di Indonesia.

Mempertahankan atau bahkan meningkatkan kinerja UKM bukan hal yang mudah. Kegagalan bisnis UKM ditengarai disebabkan oleh beberapa hal antara lain keterbatasan kapabilitas manajemen, kurang disiplin dalam keuangan dan akuntansi maupun persaingan yang berlebihan(Chittithaworn, 2011; Nangoli, 2013). Keterbatasan kapabilitas manajemen menyebabkan UKM akan kesulitan merespon peluang yang ada sedangkan masalah di bidang keuangan menyebabkan kesulitan mengakses permodalan bagi UKM (Abaho, 2016) . Akses permodalan merupakan hal yang krusial bagi perusahaan dan menjadi driver bagi inovasi (Kim, 2016; Popov, 2013).

Nilai personal entrepreneur juga merupakan elemen yang dibutuhkan oleh perusahaan. (Mashlah, 2015) menyebutkan bahwa nlai personal individu akan mempengaruhi cara mereka berpikir, merasa, dan bertindak di tempat kerja. Kombinasi nilai personal dalam manajer dan sumber daya organisasi akan membangun dasar untuk bersikap terdapat sifat inovasi mereka (Daghfous, 2007; Kask, 2011). Sementara itu inovasi dituntut untuk mampu meningkatkan kinerja perusahaan. Bagi UKM, inovasi mampu meningkatkan produktivitas. UKM. (Bakar \& Ahmad, 2010) menambahkan bahwa kemampuan dalam inovasi produk dan bisnis sangat penting bagi perusahaan untuk mengeksploitasi peluang baru dan untuk mendapatkan keunggulan kompetitif.

Pemahaman tersebut diatas telah menunjukkan bahwa kapabilitas manajemen, akses pendanaan maupun nilai personal entrepeneur merupakan hal penting dalam inovasi dan penentu kinerja UKM. Selain itu, penelitian tentang pengaruh kapabilitas manajemen, pendanaan dan nilai personal entrepreneur terhadap kinerja UKM di Indonesia secara umum belum ditemukan dari literature yang ada. Oleh karena itu, penelitian ini, perlu dilakukan sehingga kinerja UKM dapat dipertahankan dan eksistensi UKM juga dapat terjaga. UKM dengan kinerja yang baik akan memberi dampak positif bagi perekonomian negara. Selain itu dengan penelitian ini maka akan memberi wawasan UKM untuk dapat meningkatkan inovasi dan kinerja bisnisnya melalui harmonisasi kapabilitas manajemen, akses pendanaan dan nilai personal entrepreneur. UKM yang senantiasa memperhatikan ketiga hal tersebut akan memiliki kemampuan inovasi yang baik sehingga mampu mengubah peluang pasar yang ada 


\section{Buletin Ekonomi}

menjadi produk bernilai tambah dan memenuhi kebutuhan pelangganya. Hal ini tentu saja berdampak pada kinerja dan daya saing UKM.

Kapabilitas manajemen merupakan hal yang krusial dalam menentukan kemampuan inovasi perusahaan. Manajemen dengan kapabilitas yang dimilikinya akan senantiasa melakukan penyesuaian antara sumber daya internal yang dimilikinya dengan tujuan organisasi maupun lingkungan eksternal. Keberhasilan inovasi dapat dicapai apabila perusahaan mampu menyesuaikan antara sumber daya yang dimilikinya dengan harapan pasar bisnisnya (Pufal, 2015). Penelitian (Ruiz-Jiménez, 2016) maupun (Ali, 2017) menyebutkan adanya hubungan yang kuat dan signifikan antara kemampuan management terhadap inovasi yang dilakukan UKM.

Dewasa ini pemerintah telah mendukung semua sektor usaha tak terkecuali UKM. Namun yang menjadi hambatan UKM adalah dari sisi keuangan dimana keuangan merupakan sumber daya berkelanjutan yang sangat dibutuhkan setiap waktu dan setiap aktivitas. Keuangan atau uang merupakan sumber daya perusahaan yang paling likuid dan dapat digunakan untuk berbagai hal antara lain investasi, inovasi dan pemenuhan transaksi harian perusahaan. Oleh karena itu suatu perusahaan harus memperhatikan kemampuan mengakses pendanaan untuk permodalan bagi inovasi perusahaan. Perusahaan dapat menggunakan sumber internal dan eksternal untuk membiayai inovasi. Biaya modal internal biasanya lebih rendah daripada biaya modal eksternal namun ketersediaan modal internal terbatas sehingga perusahaan tetap membutuhkan modal eksternal. Modal eksternal sangat digemari oleh entrepreneur karena tetap mempertahankan kendali penuh atas perusahaan mereka. Oleh karena itu kemudahan akses modal eksternal sangat dibutuhkan oleh UKM (Lee, 2015). Penelitian yang dilakukan oleh (Fowowe, 2017) dengan ukuran obyektif menunjukan bahwa perusahaan akan mengalami pertumbuhan yang lebih cepat apabila tidak mengalami kendala dalam masalah pendanaan. Hal ini menggambarkan bahwa pendanaan sangat penting dalam menunjang pertumbuhan perusahaan.

Pertumbuhan akses keuangan UKM memungkinkan wirausahawan untuk berinovasi, meningkatkan efisiensi, memperluas ke pasar baru, dan menyediakan jutaan pekerjaan. Namun, di negara-negara berkembang, mayoritas UKM tidak dapat memperoleh pembiayaan yang mereka butuhkan untuk mencapai potensi mereka. Menurut (Fowowe, 2017) salah satu faktor yang membatasi kelangsungan hidup dan pertumbuhan UKM tidak tersedianya pembiayan hutang. Namun akses ke keuangan telah diidentifikasi sebagai masalah paling penting yang dihadapi UKM. Kurangnya akses ke pembiayaan bagi UKM sebagai salah satu hambatan utama untuk pertumbuhan.

Beberapa penelitian menegaskan pentingnya perilaku karyawan perusahaan dalam perkembangan inovasi suatu perusahaan. Penelitian tentang perilaku mengungkapkan pengaruh nilai-nilai personal karyawan sebagai bagian dari sumber daya yang tersedia untuk dapat berperan dalam mengembangan inovasi perusahaan. Penelitian yang dilakukan (Potocan, 2013) menjelaskan adanya nilai-nilai perilaku manajer akan mengarah pada tindakan inovasi yang mereka lakukan. Karakter pribadi ambisi, kesuksesan, kebebasan, dan kesediaan menolong memiliki hubungan positif dengan perilaku inovatif individu. Pengaruh nilai-nilai personal seperti kreativitas dan ambisi akan mempengaruhi inovasi yang dilakukan oleh karyawan di Negara Kroasia (Dabic, 2017).

Ling et al. (2007) menyebutkan bahwa nilai-nilai personal merupakan karakteristik pemimpin yang akan memberi pengaruh bagi pertumbuhan penjualan perusahaan. Bukti ini mendukung anggapan bahwa kinerja perusahaan merupakan cerminan dari nilai-nilai dan basis kognitif dari anggota perusahaan. Oleh karena itu, nilai adalah kunci untuk memahami hubungan antara karakteristik pribadi pengusaha dan kinerja perusahaan. 


\section{Buletin Ekonomi}

Shariff and Peou (2008) menunjukkan bahwa entrepreneur pada UKM yang memiliki nilai-nilai kewirausahaan antara lain seperti kreativitas, integritas, prestasi cenderung memiliki kinerja yang unggul dalam mengelola perusahaan dibandingkan dengan entrepreneur yang tidak memiliki nilai-nilai tersebut. Adapun hipotesis pertama yang dikembangkan:

H1a : Kapabilitas Manajemen berpengaruh signifikan terhadap Inovasi

$\mathrm{H} 1 \mathrm{~b}$ : Akses Pendanaan berpengaruh signifikan terhadap Inovasi

H1c : Nilai Personal Entrepeneur berpengaruh signifikan terhadap Inovasi

Pada kerangka ekonomi global, UKM harus mampu mempertahankan posisinya diantara para pesaing global. Inovasi merupakan sarana UKM untuk mencapai keunggulan kompetitif dan keunggulan profitabilitas. Inovasi adalah proses pengolahan ide untuk menciptakan kekayaan baru maupun meningkatkan sumber daya yang ada menjadi kekayaaan baru. Inovasi berkaitan dengan produk, proses, maupun factor (Otero-Neira, Lindman, \& Fernández, 2009). Beberapa penelitian menunjukkan hubungan positif antara inovasi dan kinerja perusahaan (Huang, 2017; Rosli, 2013). Adapun hipotesis kedua yang dikembangkan:

H2 : Inovasi berpengaruh signifikan terhadap Kinerja UKM

Kapabilitas manajemen merupakan sumber daya krusial untuk keberhasilan UKM karena entrepreneur yang memiliki kapabilitas manajemen yang baik akan mudah melakukan pengambilan keputusan strategis dan melakukan implementasinya (Rungani, 2015). Adapun penelitian (Sarwoko, 2013) menemukan bahwa kompetensi entrepreneur memiliki pengaruh signifikan terhadap kinerja bisnis. Ketrampilan entrepreneur dalam melakukan perencanaan dan penganggaran akan mendukung keberhasilan usaha UKM (Agbim, 2013; Mohammed, 2014; Thaimuta, 2014). Sedangkan (Kamunge, 2014) menyebutkan bahwa keterampilan dan pengalaman yang dimiliki manajerial akan mempengaruhi bisnis yang dilakukan. Adapun kapabilitas dinamik dan koordinasi organisasional mampu meningkatkan kinerja perusahaan (Huang, 2017).

Kinerja UKM tidak mungkin tercapai tanpa adanya modal yang cukup. Modal keuangan merupakan sumber kerbelanjutan UKM yang akan digunakan untuk melakukan investasi, inovasi maupun perluasan pasar. Beberapa penelitian menunjukkan bahwa mayoritas UKM tidak memperoleh cukup modal yang dibutuhkan namun bukti empiris justru menyebutkan bahwa kredit yang dibutuhkan UKM akan membawa dampak positif bagi perkembangan dan kinerja UKM (Evbuomwan, 2013; Onakoya, 2013; Sambo, 2015).

Nilai-nilai memberikan penjelasan yang kuat tentang perilaku individu (M. J. Gorgievski, Ascalon, M.E. \& Staphan, U. , 2011). Nilai akan berlaku sebagai standar untuk mengevaluasi dan menilai perilaku dan membentuk dasar persepsi individu. Oleh karena itu nilai personal entrepreneur sangat menentukan keputusan yang diambil manajemen dan kinerja perusahaan. Hasil penelitian (Ling, 2007) mengakui bahwa nilai-nilai pribadi entrepreneur sangat berpengaruh pada pertumbuhan penjualan perusahaan hal ini berarti bahwa kinerja perusahaan merupakan refleksi dari kemampuan kognitif individu dalam organisasi. Pemilik bisnis yang memiliki nilai-nilai pribadi seperti kreativitas, integritas, prestasi, lebih mungkin memiliki kinerja yang unggul (Shariff \& Peou, 2008; Zainol, 2011). Adapun hipotesis ketiga yang dikembangkan:

H3a : Kapabilitas Manajemen berpengaruh signifikan terhadap Kinerja UKM

$\mathrm{H} 3 \mathrm{~b}$ : Akses pendanaan berpengaruh signifikan terhadap Kinerja UKM

$\mathrm{H} 3 \mathrm{c}$ : Nilai personal entrepreneur berpengaruh signifikan terhadap Kinerja UKM

2.4. Kerangka Pikir Penelitian 


\section{Buletin Ekonomi}

Penelitian ini meneliti mengenai pengaruh kompetensi sosial, relasional jejaring dan orientasi berbagi pengetahuan terhadap kinerja bisnis perusahaan. Secara piktografis pengaruh tersebut dapat dilihat pada kerangka pemikiran sebagai berikut:

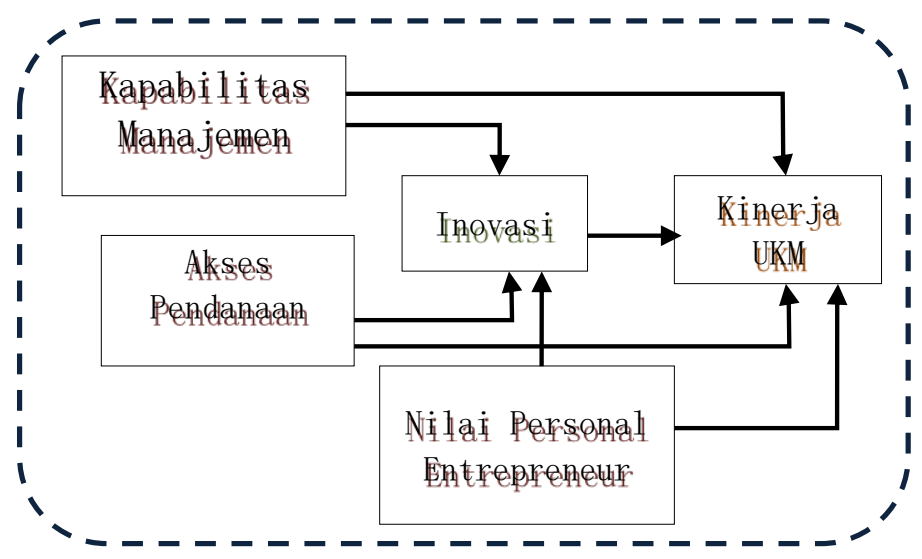

Gambar 1 : Model Penelitian.

\section{METODE}

Populasi penelitian ini adalah seluruh UKM di Surakarta. Unit analisis adalah pemilik UKM karena mereka pihak yang mengetahui keadaan di dalam usahanya Non Random sampling digunakan sebagai metode pengambilan sampling dengan teknik convenience sampling sebagai teknik memilih sample. Jumlah sampel minimum penelitian sebanyak 125 UKM dengan perhitungan $5 \times 25$ indikator. Pertimbangan jumlah ideal minimal sampel yang diperlukan untuk proses analisis menggunakan PLS adalah 5-10 responden untuk setiap parameter (Ghozali, 2008). Adapun data yang digunakan adalah data primer dengan metode pengumpulan data yaitu kuesioner dengan pernyataan tertutup.

Seluruh variabel penelitian akan diukur dengan 5 skala likert antara sangat tidak setuju untuk skala 1 sampai dengan setuju dengan skala 5. Adapun definisi operasional kapabilitas manajemen adalah satu kombinasi antara pengetahuan, keterampilan, perilaku dan sikap yang dapat berkontribusi pada efektivitas kerja perusahaan (Hellriegel, 2008). Adapun pengukurannya dengan 6 indikator dari penelitian yang dilakukan (Bakanauskiene, 2011) dan (Veliu \& Manxhari, 2017). Akses Pendanaan adalah kemampuan perusahaan untuk mendapatkan pelayanan keuangan dari pihak eksternal. Akses pendanaan diukur dengan 4 indikator yang diadopsi dari (Fowowe, 2017) dan (Contessi \& De Nicola, 2012).

Nilai Personal entrepreneur adalah nilai-nilai yang melekat dalam diri entrepreneur yang mampu mempengaruhi cara berpikir, merasakan dan bertindak yang pada akhirnya akan membantu individu dalam melakukan pengambilan keputusan secara benar (Mashlah, 2015). Pengukuran variabel ini dengan 4 indikator yang diadopsi dari penelitian (Potocan, 2013). Kapabilitas Inovasi adalah sebagai proses peningkatan produk dan layanan sehingga dapat menarik selera dan permintaan pelanggan maupun dapat meningkatkan kemampuan karyawan (Olughor 2015). Pengukuran kapabilitas inovasi diadopsi dari penelitian (Sajeva, 2008; Valdez-Jualrez, 2016) yang terdiri dari 4 indikator. Kinerja UKM adalah ukuran efektifitas dan efisiensi perusahaan dalam mencapai tujuan bisnisnya (Nakata, 2008). Pengukuran menggunakan Questionnaire of Entrepreneurial Success yang diadopsi dari (Wiklund, 2005) yang terdiri dari 5 indikator.

Statistik diskriptif akan digunakan untuk mengawali teknik analisis data yang meliputi demografi responden (jenis kelamin, pendidikan, usia perusahaan, jenis usaha) selain itu akan 


\section{Buletin Ekonomi}

disajikan tabel distribusi frekuensi absolut akan menunjukkan rata-rata, median, kisaran dan deviasi standar.

Pengujian kualitas data dilakukan dengan pengujian reliabilitas dan pengujian validitas. Pengujian reliabilitas dengan melihat nilai composite reliability dan Average Variance Extracted (AVE). Adapun pengujian validitas dilakukan dengan convergent validity yaitu melihat nilai loading factor. Suatu konstruk dikatakan reliable apabila memiliki nilai minimal 0,7 untuk composite reliable dan 0,5 untuk AVE sedangkan nilai loading faktor yang disyaratkan sebagai data valid adalah minimal 0,5 (Ghozali, 2008).

Pengambilan keputusan hipotesis berdasarkan analisis Structural Equation Model (SEM) yaitu dengan menggunakan Partial Least Square (PLS). SEM dengan PLS akan mampu mengestimasi model yang kompleks dengan sampel kecil, tidak mengasumsikan data harus terdistribusi secara normal (non-parametrik), indikator dapat dibentuk secara formatif (cause) dan refleksi (effect) dan PLS lebih berorientasi pada prediksi(Ghozali, 2008). Software yang akan digunakan adalah Smart PLS. Adapun persamaan yang dibentuk adalah :

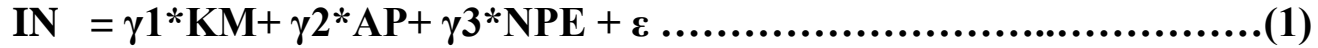

$\mathrm{KJ}=\gamma 1 * \mathrm{KM}+\gamma 2 * \mathrm{AP}+\gamma 3 * \mathrm{NPE}+\gamma 4 * \mathrm{IN}+\varepsilon \ldots \ldots \ldots \ldots \ldots \ldots \ldots \ldots \ldots \ldots(2)$

Keterangan : KJ : Kinerja UKM, KM : Kapabilitas Manajemen, IN :Inovasi, AP : Akses Pendanaan, NPE: Nilai Personal Entrepreneur, $\varepsilon$ : Error.

\section{ANALISIS DAN PEMBAHASAN}

Terdapat 125 sampel yang diperoleh dari para pemilik UKM di wilayah Kota Surakarta akan dianalisis untuk pengambilan keputusan dalam pengujian hipotesis. Profil dari 125 responden sebagian besar adalah laki-laki sebanyak 68 orang (54,4\%). Usia responden terbanyak pada usia 41 - 50 tahun yaitu sebanyak 51 orang atau 40,8\%. Pendidikan responden didominasi dengan pendidikan tingkat SMA/SMK yaitu sebesar 51 orang (40,8\%). Adapun mayoritas bidang usaha UKM yang terlibat adalah sektor manufaktur 66 UKM atau sebesar 52,8\% dengan umur usaha 11 - 20 tahun sebanyak 55 UKM atau 44\%.

Pengujian reliabilitas dilakukan dengan melihat nilai composite reliability dan cronbach alpha dari blok indikator yang mengukur masing-masing konstruk. Berdasarkan tabel 1 maka nilai composite reliability dan cronbach alpha menunjukkan nilai yang memuaskan yaitu nilai composite reliability dan cronbach alpha yang sangat baik yaitu nilai masing-masing konstruk di atas nilai minimum yang dipersyaratkan yaitu 0,70 . Hal ini dapat dikatakan bahwa terdapat konsistensi dan stabilitas instrumen penelitian yang tinggi atau dapat disimpulkan bahwa kelima konstruk tersebut cukup reliable untuk dapat digunakan dalam penelitian.

Tabel 1. Hasil Pengujian Reliabilitas

\begin{tabular}{lcc}
\hline & Composite Reliability & Cronbach Alpha \\
\hline Kinerja UKM & 0,857 & 0,794 \\
Kapabilitas Manajemen & 0,834 & 0,750 \\
Akses Pendanaan & 0,868 & 0,817 \\
Nilai Personal Entrepreneur & 0,874 & 0,810 \\
Inovasi & 0,890 & 0,836 \\
\hline
\end{tabular}

Sumber : Data diolah, 2019

Pada pengujian validitas maka hasil loading factor akan menunjukkan convergent validity. Suatu konstruk laten akan mempredikasi indikator pada blok mereka lebih baik dibandingkan dengan indikator di blok lainnya apabila nilai korelasi dengan indikatornya 


\section{Buletin Ekonomi}

memiliki nilai lebih tinggi (Ghozali, 2015). Hal ini juga mengandung makna bahwa indikator konstruk tersebut valid. Untuk memperjelaskan maka hasil analisis disajikan pada tabel 2.

Tabel 2. Cross Loading Indikator antar Construct

\begin{tabular}{lrrrrr}
\hline & $\begin{array}{r}\text { Kapabilitas } \\
\text { Manajemen }\end{array}$ & $\begin{array}{c}\text { Akses } \\
\text { Pendanaan }\end{array}$ & $\begin{array}{c}\text { Nilai Personal } \\
\text { Entrepreneur }\end{array}$ & Inovasi & $\begin{array}{c}\text { Kinerja } \\
\text { UKM }\end{array}$ \\
\hline KM.1 & $\mathbf{0 , 6 6 0}$ & 0,051 & 0,252 & 0,284 & 0,442 \\
KM.2 & $\mathbf{0 , 7 8 9}$ & 0,174 & 0,143 & 0,358 & 0,419 \\
KM.3 & $\mathbf{0 , 7 2 0}$ & 0,207 & 0,156 & 0,418 & 0,427 \\
KM.4 & $\mathbf{0 , 7 5 3}$ & 0,286 & 0,157 & 0,291 & 0,402 \\
KM.5 & $\mathbf{0 , 6 0 9}$ & 0,465 & 0,292 & 0,383 & 0,536 \\
AD.1 & 0,294 & $\mathbf{0 , 7 1 6}$ & 0,101 & 0,193 & 0,291 \\
AD.2 & 0,325 & $\mathbf{0 , 8 5 6}$ & $-0,143$ & 0,318 & 0,251 \\
AD.3 & 0,127 & $\mathbf{0 , 6 2 2}$ & 0,142 & 0,413 & 0,460 \\
AD.4 & 0,335 & $\mathbf{0 , 8 2 1}$ & $-0,152$ & 0,306 & 0,245 \\
AD.5 & 0,295 & $\mathbf{0 , 7 4 3}$ & 0,135 & 0,192 & 0,305 \\
NPE1 & 0,147 & $-0,136$ & $\mathbf{0 , 7 5 9}$ & 0,120 & 0,408 \\
NPE2 & 0,157 & 0,061 & $\mathbf{0 , 8 4 0}$ & 0,198 & 0,527 \\
NPE3 & 0,252 & 0,075 & $\mathbf{0 , 8 3 6}$ & 0,287 & 0,550 \\
NPE4 & 0,376 & 0,077 & $\mathbf{0 , 7 5 0}$ & 0,179 & 0,421 \\
IN.1 & 0,519 & 0,219 & 0,418 & $\mathbf{0 , 7 9 0}$ & 0,687 \\
IN.2 & 0,175 & 0,392 & 0,122 & $\mathbf{0 , 8 0 1}$ & 0,492 \\
IN.3 & 0,428 & 0,405 & 0,131 & $\mathbf{0 , 7 9 1}$ & 0,555 \\
IN.4 & 0,444 & 0,350 & 0,104 & $\mathbf{0 , 8 8 9}$ & 0,529 \\
KJ.1 & 0,498 & 0,284 & 0,439 & 0,462 & $\mathbf{0 , 6 5 3}$ \\
KJ.2 & 0,632 & 0,382 & 0,601 & 0,654 & $\mathbf{0 , 8 5 9}$ \\
KJ.3 & 0,617 & 0,293 & 0,450 & 0,490 & $\mathbf{0 , 7 1 2}$ \\
KJ.4 & 0,287 & 0,393 & 0,290 & 0,508 & $\mathbf{0 , 7 4 5}$ \\
\hline umbr: Data & 2019 & & & &
\end{tabular}

Sumber : Data diolah, 2019

\subsection{Hasil Pengujian Model Struktural (Inner Model)}

Pengujian model structural (Inner Model) digunakan untuk melihat hubungan antara konstruk, nilai signifikansi serta nilai $R$-square. Nilai $R$-square akan digunakan untuk menilai pengaruh variabel independen terhadap variabel dependen apakah memiliki pengaruh yang substantif. Nilai $R$-square ditunjukkan pad tabel 3 yang menunjukkan nilai sebesar 0,779 pada konstruk kinerja UKM dan 0,330 pada konstruk inovasi. Hal ini berarti bahwa konstruk kinerja UKM dapat dijelaskan oleh konstruk kemampuan manajemen, akses pendanaan, nilai personal entrepreneur dan inovasi sebesar 77,9\% sedangkan 22,1\% dapat dijelaskan oleh faktor-faktor lain selain keempat konstruk tersebut. Adapun konstruk inovasi itu sendiri dapat dijelaskan oleh konstruk kapabilitas manajemen, akses pendanaan, nilai personal entreprnenur sebesar 33\% sedangkan sisanya sebesar $67 \%$ dapat dijelaskan oleh faktor-faktor lain selain ketiga konstruk tersebut.

\begin{tabular}{lc}
\multicolumn{2}{c}{ Table 3: Nilai $\boldsymbol{R}$-square } \\
\hline Konstruk & R-square \\
\hline Kinerja UKM & 0,779 \\
Inovasi & 0,330 \\
\hline Sumber : Data primer diolah, 2019
\end{tabular}




\section{Buletin Ekonomi}

Pengujian untuk melihat hubungan antar konstruk atau uji hipotesis dapat dilihat dengan melihat koefisien parameter dan membandingkan antara nilai t-hitung dan t-tabel pada signifikasi sebesar 0,05. Tabel 4 menunjukkan hasil hubungan antar konstruk atau uji hipotesis penelitian sebagai berikut:

Tabel 4: Hasil Statistik Inner Model

\begin{tabular}{lccc}
\hline \multicolumn{1}{c}{ Hubungan Kausalitas Konstruk } & $\begin{array}{c}\text { Koefisisen } \\
\text { Estimasi }\end{array}$ & t-Statistik & $\boldsymbol{P}$ Value \\
\hline Kapabilitas Manajemen $\rightarrow$ Kinerja UKM & 0,258 & 4,135 & 0,000 \\
Kapabilitas Manajemen $\rightarrow$ Inovasi & 0,362 & 5,109 & 0,000 \\
Akses Pendanaan $\rightarrow$ Kinerja UKM & 0,175 & 2,509 & 0,012 \\
Akses Pendanaan $\rightarrow$ Inovasi & 0,277 & 3,415 & 0,001 \\
Nilai Personal Entreprenenur $\rightarrow$ Kinerja UKM & 0,424 & 7,752 & 0,000 \\
Nilai Personal Entreprenenur $\rightarrow$ Inovasi & 0,141 & 2,079 & 0,038 \\
Inovasi $\rightarrow$ Kinerja UKM & 0,397 & 4,322 & 0,000 \\
\hline
\end{tabular}

Sumber : Data primer diolah, 2019

Hasil analisis PLS pada tabel 4 dapat dinyatakan dalam persamaan struktural sebagai berikut :

Inovasi $\quad=0,362$ Kapabilitas Manajemen + 0,277 Akses Pendanaan + 0,141 Nilai

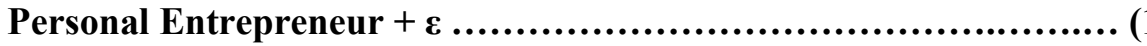

Kinerja UKM = 0,258 Kapabilitas Manajemen+ 0,175 Akses Pendanaan + 0,424 Nilai

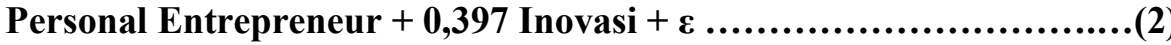

\section{Pembahasan}

Hasil analisis menggunakan 125 sampel UKM menunjukkan hipotesis satu sampai dengan hipotesis ketujuh diterima yaitu ditemukan adanya pengaruh antara variabel independen terhadap dependennya. Hasil analisis pada kapabilitas manajemen memiliki pengaruh signifikan terhadap inovasi dengan t statistik sebesar 5,109 $(>1,96)$ dengan $p$ value sebesar $0,000(<0,05)$ dan nilai original sample estimate adalah positif sebesar 0,362 maka arah pengaruh kapabilitas manajemen dengan inovasi adalah positif. Kemampuan manajemen memiliki kontribusi dalam membangun kemampuan kognitif anggota perusahaan untuk mengelola sumber daya yang dimiliki sehingga pada akhirnya akan dapat mempengaruhi implementasi strategi dan mencari alternatif-alternatif untuk pengembangan dan inovasi perusahaan.

Akses pendanaan juga memiliki pengaruh terhadap inovasi. Hal ini didasarkan pada nilai t statistik sebesar 3,415 $(>1,96)$ dengan nilai $p$ value sebesar $0,001(<0,05)$. Sedangkan nilai original sample estimate sebesar 0,277 menunjukkan nilai pengaruh yang positif. Kemudahan melakukan akses pendanaan akan memudahkan perusahaan untuk mengadopsi tehnologi. Perusahaan dengan teknologi yang ada akan mengeksploitasi research and development untuk dapat menghasilkan produk untuk memenuhi kebutuhan pasarnya.

Nilai personal entrepreneur memiliki pengaruh juga terhadap inovasi dimana nilai $\mathrm{t}$ statistik sebesar $2,079(>1,96)$ dengan nilai $p$ value sebesar $0,038(<0,05)$ sedangkan nilai original sample estimate adalah sebesar 0,141 yang berarti terdapat pengaruh positif antara nilai personal entrepeneur dengan inovasi. Keterlibatan entrerpeneur pada proses inovasi dalam perusahaan ditentukan oleh nilai-nilai personal (kepercayaan diri, kemadirian, pengambilan risiko atau keterbukaan)yang melekat dalam diri entrepreneur tersebut. Semakin memiliki nilai nilai personal yang positif maka seorang entrepreneur cenderung akan melakukan inovasi dalam perusahaannnya. 


\section{Buletin Ekonomi}

Pada tabel 4 juga menunjukkan bahwa inovasi memiliki pengaruh pada kinerja UKM dimana t statistik memiliki nilai sebesar 4,322 (>1,96) dengan $p$ value sebesar $0,000(<0,05)$ sedangkan nilai original sample estimate sebesar 0,397. Hal ini menunjukkan bahwa inovasi memiliki pengaruh yang positif pada kinerja UKM. Persaingan global yang semakin ketat menjadi driver UKM untuk lebih fokus melakukan berbagai strategi termasuk inovasi dengan harapan perusahaan akan memperoleh keunggulan kompetitif untuk mempertahankan dan mengembangkan kinerjanya.

Kapabilitas manajemen juga menunjukkan memiliki pengaruh pada kinerja UKM dengan nilai t statistik sebesar 4,135 $(>1,96)$ dengan nilai $p$ value sebesar $0,000(<0,05)$ dan nilai original sample estimate adalah sebesar 0,258 . Hal ini berarti terdapat pengaruh yang positif antara kapabilitas manajemen dengan kinerja UKM. Keberhasilan UKM akan dapat dicapai apabila UKM mampu mempertahankan kapabilitas manajemen yang baik. Oleh karena itu, UKM harus mampu melakukan kombinasi yang tepat antara pengetahuan, keterampilan, perilaku dan sikap sehingga kapabilitas manajemen dapat terbentuk sebaikbaiknya dalam perusahaan.

Selanjutnya, akses pendanaan memiliki pengaruh terhadap kinerja UKM. Hal ini didasarkan pada nilai t statistik sebesar 2,509 (> 1,96) dengan nilai $p$ value sebesar 0,012 (< $0,05)$. Sedangkan nilai pada original sample estimate sebesar 0,175 menunjukkan nilai pengaruh yang positif. Aksesbilitas dana yang mudah memungkinkan UKM untuk mendapatkan modal kerjanya sehingga akan meningkatkan kemampuan melakukan produksi. Hal ini tentu saja akan berdampak pada kinerja UKM terutama kinerja keuangannya.

Nilai personal entrepreneur memiliki pengaruh juga terhadap kinerja UKM dimana nilai t statistik sebesar 7,752 $(>1,96)$ dengan nilai $p$ value sebesar $0,000(<0,05)$ sedangkan nilai original sample estimate adalah sebesar 0,424 yang berarti terdapat pengaruh positif antara nilai personal entrepeneur dengan kinerja UKM. Nilai-nilai personal entrepreneur akan dapat mempengaruhi cara berpikir, merasakan dan bertindak entrepreneur dalam melakukan kegiatan bisnisnya. Nilai-nilai entrepreneur yang melekat dalam diri entrepreneur akan menjadi pondasi penting dalam melakukan pengambilan keputusan secara tepat. Pengambilan keputusan yang tepat tentu saja dibutuhkan untuk mempertahankan kinerja UKM.

\section{KESIMPULAN DAN SARAN}

Analisis dari 125 UKM di Kota Surakarta yang terdiri dari 66 UKM sektor manufaktur dan 59 sektor jasa dapat disimpukan bahwa harmonisasi kapabilitas manajemen, akses pendanaan dan nilai entrepreneur mampu meningkatkan inovasi dan kinerja UKM. Selanjutnya kesimpulan untuk masing-masing hipotesis adalah sebagai berikut :

1. Kapabilitas manajemen memiliki pengaruh pada inovasi. Hasil penelitian ini konsisten dengan penelitian yang dilakukan oleh Ruiz-Jiménez (2016) maupun Ali (2017). Kapabilitas manajemen diyakini mampu mengorganisasi seluruh kegiatan dalam perusahaan sehingga kegiatan yang terorganisasi tersebut akan dapat selaras dengan strategi perusahaan. Keberhasilan inovasi dapat dicapai apabila perusahaan mampu menyesuaikan antara sumber daya yang dimilikinya dengan peluang pasar bisnisnya.

2. Akses pendanaan memiliki pengaruh terhadap inovasi. Penelitian ini konsisten dengan penelitian yang dilakukan oleh Lee (2015) dan Fowowe (2017). Akses pendanaan memungkinkan UKM untuk dapat memperoleh sumber daya yang dibutuhkan sehingga mampu mendorong inovasi dalam berbagai aspek baik manajemen maupun teknologi. 


\section{Buletin Ekonomi}

3. Nilai personal entrepreneur memiliki pengaruh terhadap inovasi. Hasil penelitian ini sejalan dengan penelitian yang dilakukan oleh Potocan (2013), Dabic (2017) dan Shariff and Peou (2008). Karakter pribadi seperti ambisi, altruistic, kreativitas maupun integritas yang melekat dalam anggota perusahaan mampu mengembangkan jiwa kewirausahaan yang mengarah pada tindakan inovasi perushaaan.

4. Inovasi berpengaruh pada kinerja UKM. Penelitian yang dilakukan oleh Huang (2017) dan (Rosli, 2013) menekankan pentingnya inovasi pada kinerja UKM. Inovasi akan memenuhi kebutuhan pelanggan dan menjadi keunggulan kompetitif perusahaan sehingga perusahaan mampu meningkatkan kinerjanya baik finansial maupun non finansial.

5. Kapabilitas manajemen berpengaruh pada kinerja UKM. Hasil penelitian ini konsisten dengan penelitian yang pernah dilakukan oleh Agbim (2013), Thaimuta (2014), Mohammed (2014), dan Huang (2017) dimana kompetensi dan ketrampilan yang dimiliki entrepreneur menjadi dasar seorang entrepreneur melakukan perencanaan yang matang dalam aktivitas bisnisnya sehingga akan membawa dampak positif pada kinerja bisnis UKM.

6. Akses pendanaan berpengaruh pada kinerja UKM. Penelitian yang dilakukan oleh Evbuomwan (2013), Onakoya (2013) dan Sambo (2015) sejalan dengan penelitian ini dimana modal usaha merupakan hal yang krusial sebagai sumber keberlanjutan UKM. Akses pendanaan yang mudah akan membawa dampak positif bagi eksistensi dan pengembangan kinerja UKM dimasa yang akan datang.

7. Nilai personal entrepreneur berpengaruh pada kinerja UKM. Penelitian yang telah dilakukan memberi hasil yang konsisten dengan penelitian yang dilakukan oleh Ling (2007), Shariff and Peou (2008), Zainol (2011) dan M. J. Gorgievski, Ascalon, and Stephan (2011). Sangat perlu untuk menyelaraskan nilai personal individu dengan nilainilai perusahaan. Nilai-nilai pribadi entrepreneur UKM sangat mungkin untuk menentukan pengambilan keputusan. Pengambilan keputusan yang efektif nantinya akan dapat berdampak pada keberhasilan UKM

Adapun saran yang bisa diberikan dari hasil penelitian ini adalah :

1. Untuk mendapatkan hasil yang lebih reliable maka jumlah responden dapat diperbesar dan lokasi geografis penelitian dapat diperluas.

2. Metode pengumpulan data dapat dikombinasi dengan mengunakan teknik wawancara sehingga data yang berhasil dikumpulkan dapat lebih diandalkan.

Keterbatasan dalam penelitian ini adalah ukuran sampel yang kecil dibandingkan dengan populasi UKM yang ada di Kota Surakarta menyebabkan kemampuan untuk mewakili seluruh UKM Di Kota Surakarta relatih kecil pula. Hal ini menyebabkan hasil penelitian memiliki kemampuan generalisasi yang rendah.

\section{UCAPAN TERIMA KASIH}

1. Direktorat Riset dan Pengabdian Masyarakat, Direktorat Jenderal Penguatan Riset dan Pengembangan Kementerian Riset, Teknologi, dan Pendidikan Tinggi

2. LLDIKTI Wilayah VI, Jawa Tengah

3. LPPM STIE Atma Bhakti, Surakarta.

\section{DAFTAR PUSTAKA}




\section{Buletin Ekonomi}

Abaho, E., Sylvia, A., Ntayi, J.M., \& Kisubi, M.K. (2016). Firm Capabilities, Entrepreneurial Competency And Performance Of Ugandan SMEs. Business Management Review, 19(2), 105-125.

Agbim, K. C. (2013). The Relative Contribution of Management Skills to Entrepreneurial Success: A Survey of Small and Medium Enterprises (SMEs) in the Trade Sector. OSR Journal of Business and Management, 7(1), 08 - 16.

Ali, Z., Sun, H, \& Ali, M. (2017). The Impact of Managerial and Adaptive Capabilities to Stimulate Organizational Innovation in SMEs: A Complementary PLS-SEM Approach. Sustainability, 9, 2-23.

Bakanauskiene, I., \& Martinkiene, J. (2011). Determining managerial competencies of management professionals: Business companies managers' approach in Western Lithuania region. Organizaciju Vadyba: Sisteminiai Tyrimai, 60.

Bakar, L. J. A., \& Ahmad, H. (2010). Assessing the Relationship Between Firm Resources and Product Innovation Performance a Resource Based View. Journal of Business Process Management, 16(3), 420-435.

Chittithaworn, C., Islam, M. A., Keawchana, \& Yusuf, D.H.M. (2011). Factors affecting business success of small and medium enterprises (SMEs) in Thailand. . Asian Social Science, 7, 180190.

Contessi, S., \& De Nicola, F. (2012). What Do We Know about the Relationship between Access to Finance and International Trade? .

Dabic, M., Potocan, V., \& Nedelko, Z, . (2017). Personal values supporting enterprises' innovations in the creative economy. Journal Of The Knowledge Economy. , 8 (4), 1241-1261.

Daghfous, A. (2007). Absorptive capacity and innovative enterprise systems: A two-level framework. International Journal of Innovation and Learning, 4(1), 60-73.

Evbuomwan, G. O., Ikpi, A.E. , Okoruwa, V.O. \& Akinyosoye, V.O. (2013). Sources of Finance for Micro, Small and Medium Enterprises in Nigeria. Paper presented at the 19th International Farm Management Congress, Poland.

Fowowe, B. (2017). Access to finance and firm performance: Evidence from African countries. Review of Development Finance, 7, 6-17.

Ghozali, I. (2008). Struktural Equation Modelling Metode Alternatif dengan Partial Least Square. Semarang: Universitas Diponegoro.

Gorgievski, M. J., Ascalon, M. E., \& Stephan, U. (2011). Small business owners' success criteria, a values approach to personal differences. Journal of Small Business Management, 49(2), 207232.

Gorgievski, M. J., Ascalon, M.E. \& Staphan, U. . (2011). Small business owners' success criteria: a value approach to personal differences. Journal of Small Business Management, 49(2), 207232. 


\section{Buletin Ekonomi}

Hellriegel, D., Jackson, S.E., Slocum, J., Staude, G., Amos, T., Klopper, H.B., Louw, L., \& Oosthuizen, T. (2008). Management (Third South African Edition ed.). Cape Town: Oxford University Press.

Huang, J.-w., \& Li, Yong-hui.,. (2017). Green Innovation and Performance: The View of Organizational Capability and Social Reciprocity Journal of Business Ethics., 145(2), 309324.

Kamunge, M. S., Njeru, A, \& Tirimba, O. I. (2014). Factors Affecting the Performance of Small and Micro Entreprises in Limuru Town Market in Kianbu County, Kenya. . International Journal of Scientific and Research Publications, 4(12).

Kask, T. (2011). Strategic decisions as drivers of innovation: The case of Micro Link. . Baltic Journal of Management., 6(3), 300-319.

Kim, D. H., Lin, S. C. \& Chen, T.C. . (2016). Financial structure, firm size and industry growth. International Review of Economics and Finance, 41, 23-39. doi: 10.1016/j.iref.2015.10.002

Lee, N., Sameen, H., \& Cowling, M. (2015). Access to finance for innovative SMEs since the financial crisis. Research Policy, 44(2), 370-380.

Ling, Y., Zhao, H. \& Baron, R.A. (2007). The influence of founder CEOs' personal values on firm performance: moderating effects of firm age and size Journal of Management, 33(5), 673696.

Mashlah, S. (2015). The Role Of People's Personal Values In The Workplace. . International Journal of Management and Applied Science, 1(9), 158-164.

Mohammed, U. D., \& Obeleagu-Nzelibe, C. G. (2014, 13 - 14 January, 2014). Entrepreneurial Skills and Profitability of Small and Medium Enterprises (SMEs): Resource Acquisition Strategies for New Ventures in Nigeria. Paper presented at the Proceedings of 25th International Business Research Conference, Taj Hotel, Cape Town, South Africa.

Mugwon, G. A. (2007). Entrepreneurship in Nigeria, principles and practices. Enugu: Rhyee Kerex publisher.

Nakata, C., Z. Zhu. \& M.L. Kraimer. (2008). The Complex Contribution of Information Technology Capability to Business Performance. Journal of Managerial Issues, 20(4), 485-500.

Nangoli, S., Turinawe, D. D., Kituyi G. M., Kusemererwa, C. \& Jaaza., M. (2013). Towards enhancing business survival and growth rates in LDCs: An exploratory study of the drivers of business failure among SMES in Kampala-Uganda. International Journal of Humanities and Social Science, 3(8).

Olughor , R. J. (2015). Effect of Innovation on the Performance of SMEs Organizations in Nigeria Management, 5(3), 90-95.

Onakoya, A. B., Onakoya, A.O., Jimi-Salami, O. A., \& Odedairo, B.O. (2013). Energy consumption and Nigerian economic growth: an empirical analysis. . European Scientific Journal, 9(4), 2540.

Otero-Neira, C., Lindman, M. T., \& Fernández, M. J. (2009). Innovation and performance in SME furniture industries. Marketing Intelligence and Planning, 27(2), 216-232. 


\section{Buletin Ekonomi}

Popov, A., \& Roosenboom, P. (2013). Venture capital and new business creation", . Journal of Banking \& Finance, 37(12), 4695-4710. doi: 10.1016/j.jbankfin.2013.08.010

Potocan, V., \& Nedelko, Z. (2013). Innovativeness of IT Managers - Exploring Influences of Personal Values on IT Managers' Innovativeness. . Procedia Technology, 9, 291-303.

Pufal, N., Zawislak, P.A., Reichert , F.M., \& Alves, A.C. (2015). Management Capability And Innovation: What Is The Relationship? Paper presented at the International Association for Management of Technology

Rosli, M. M., \& Sidek, S.,. (2013). Impact of Innovation on the Performance of Small and Medium Manufacturing Enterprises: Evidence from Malaysia. . Journal of Innovation Management in Small \& Medium Enterprise. Vol.2013, 2013. doi: 10.5171/2013.885666.

Ruiz-Jiménez, J. M., \& Fuentes-Fuentes, M.M. (2016). Management capabilities, innovation, and gender diversity in the top management team: An empirical analysis in technology-based SMEs. BRQ Business Research Quarterly, 19(2), 107-112.

Rungani, F. A. O. O. F. E. (2015). The impact of motivations, personal values and management skills on the performance of SMEs in South Africa. African Journal of Economic and Management Studies, 6(3), 308-322.

Sajeva, S., \& Jucevicius, R. (2008). Lingking Knowledge management and organizational innovatiness. Social Sciences, 59, 50-57.

Sambo, B. S., Gichira, R., \& Yusuf, I.,. (2015). Effect of Entrepreneurial Skills Management and Funding on Small and Medium Enterprises' Performances at the Local Government Level in Northern Nigeria. International Journal of Academic Research in Business and Social Sciences, 5(6).

Sarwoko, E., Surachman Armanu, \& Hadiwidjojo, D. (2013). Entrepreneurial Characteristics and Competency as Determinants of Business Performance in SMEs. OSR Journal of Business and Management, 7(3), 31-38.

Shariff, M. N. M., \& Peou, C. (2008). The relationship of entrepreneurial values, firm financing and the management and growth performance of SMEs in Cambodia. Problems and Perspectives in Management, 6(4), 55-64.

Thaimuta, J. M., \& Moronge, M. (2014). Factors affecting the performance of matatu paratransit venture in small and medium enterprises in Nairobi Country International Journal of Current Business and Social Sciences, 1(2), 1-17.

Turyahebwa, A., Sunday, A., \& Ssekajugo, D. (2013). Financial management practices and business performance of small and medium enterprises in western Uganda African Journal of Business Management, 7(38), 3875-3885. doi: 10.5897/AJBM2013.6899

Valdez-Jualrez, I. E., Garcia-Perez de Lema, D., \& Maldonado-Guzman, G. (2016). Management of knowledge, innovation and Performance in SMEs. Interdisciplinary Journal Of Information. Knowledge and Management, 11, 141-176.

Veliu, L., \& Manxhari, M. (2017). The Impact Of Managerial Competencies On Business Performance: SME’s In Kosovo. Vadyba Journal of Management, 1(30). 


\section{Buletin Ekonomi}

Wiklund, J., \& Shepherd, D. A. (2005). Entrepreneurial Orientation and Small Firm Performance: A Configurational Approach. . Journal of Business Venturing, 20, 7191.

Zainol, F. N., \& Ayadurai, S. . (2011). Entrepreneurial orientation and firm performance: the role of personality traits in family firms in Malaysia. International Journal of Business and Social Science, 2(1), 59-71. 